Original Research Paper

\title{
Seismic Fragility Assessment of RC Frame Equipped by Visco-Elastic Dampers Using NLTHA and FNA
}

\author{
${ }^{1}$ Ali A. Rostam Alilou and ${ }^{2}$ Majid Pouraminian \\ ${ }^{1}$ Structural Engineer and Researcher, Ankara, Turkey \\ ${ }^{2}$ Department of Civil Engineering, Ramsar Branch, Islamic Azad University, Ramsar, Iran
}

Article history

Received: 25-05-2019

Revised: 26-06-2019

Accepted: 16-07-2019

Corresponding Author:

Majid Pouraminian

Assistant Professor,

Department of Civil Engineering,

Ramsar Branch, Islamic Azad

University, Ramsar, Iran

Email: m.pouraminian@iauramsar.ac.ir

Majid.pouraminian@gmail.com

\begin{abstract}
In recent years, the issue of lower computational cost and analysis time has been the important factors for the structural analysts. In the meantime, after years of its introduction as an analysis having features of nonlinear analysis, the Fast Nonlinear Analysis (FNA) claims to have a higher performance speed than other nonlinear analyses, but has been less used by the researchers in this field. This research is conducted in order to improve the accuracy of the claim for a significant difference between the duration of structural analysis using the FNA method in comparison with the Nonlinear Time History Analysis (NLTHA) in Sap2000 software. RC frame with two seismic resistant systems of Moment Resistant Frame (MRF) only and MRF equipped by visco-elastic dampers (MRF-VD) and efficiency of the FNA method has been investigated. The results indicated that in the analysis time, the structural analysis is decreased by 7-9 times, while the seismic fragility curves calculated for performance limit state of the frame does not provide an accurate estimate of the damage to the frame.
\end{abstract}

Keywords: FNA, Nonlinear Time History Analysis, Fragility Curve, Plastic Hinge, Computational Time, Visco-Elastic Damper

\section{Introduction}

Finite element analysis is one of the popular methods of structural analysis. Many researchers have used this method for analysis of micro and macro models of different structures. (Sayyar-Roudsari et al., 2018a) have carried out extensive studies on RC members by ABAQUS software. One of the most important parameters that should be investigated for structures such as bridges is the effect of impact loads due to vehicle accidents, causing progressive damages to bridges and the effect of cyclic loading due to earthquake force (Sayyar-Roudsari et al., 2018b; Soleimani et al., 2015). Moreover, (Sayyar-Roudsari et al., 2018a) have investigated comprehensive numerical and finite element studies by MATLAB and ABAQUS to identify the damage to concrete bridges and presented reinforcement strategies by composite fibers (Sayyar-Roudsari et al., 2018b; Ashrafi et al., 2018) using finite element method, have examined the nonlinear behavior of wavy steel shear walls. The optimal shape of tall arched concrete dams and concrete open arched bridge is obtained using ANSYS FEM software by (Pouraminian et al., 2017; 2015). Providing seismic fragility to study on other structures such as dam seismic performance has been done by (HaririArdebili and Saouma, 2016) and (Salem et al., 2017).

The building analysis time has always been important for design engineers. Some researchers have been studied several related topic such as performance-based seismic assessment of steel frames using endurance time analysis by (Hariri et al., 2016) to show how the analysis computational time is important as the part of design procedure. Most engineers succeeded to design a correct model of the structure with trial and error. It is obvious how a long-time analysis can be frustrating in such conditions and causes difficulties in some cases for reaching a proper analysis of the structure. Despite the advancement of technology, hardware and software, a lot of time is still required for finite element analysis in models with high dynamic degrees of freedom or nonlinear analyses. Using a simplified model to reduce the computational time for determining vibrating properties of concrete bridges. The simplified bridge model by focused mass and non-mass RC members is capable of estimating dominant bridge period with $18 \%$ error and the computational time required to calculate the vibrating properties of the bridge has been highly reduced by the simplified finite element model (Pouraminian et al., 2015). (Wilson et al., 1989) 
provided a FNA to accelerate the nonlinear dynamic analyses. This method is especially effective for structures equipped by dampers and base isolation. Also several researchers have been used FNA to study on seismic behavior of buildings using base isolation systems and dampers, (Ras et al., 2016); Islam et al., 2011). The FNA method has been developed and verified by Wilson and CSI over the past 10 years. This method intends to reduce the time of nonlinear dynamic analysis with sufficient accuracy. The applied use of this analysis method is possible by CSI. Sap 2000 finite element software (CSI, 2009). In this study, the five-story symmetric RC frame has been evaluated in two different modes with different structural systems including an RC moment resistant frame only, (Seo et al., 2015) and braced frame with visco-elastic dampers subjected to earthquakes in Abbar, Kobe, Ardabil, Varzaghan, Ahar and San Fernando and the results of analysis were separately recorded for all models in both above-mentioned analyses. In the first step, based on the software and hardware specifications by which the analyses were done, the completion time of analysis for the models is recorded and finally, based on the statistical data, the objective judgment was made. In the second step, by preparing seismic fragility curves, the seismic performance of the structures was studied in accordance with valid codes such as ASCE and the process of work and the results are presented in the article.

FNA can be used for both nonlinear static and dynamic analysis of structural systems, assuming that the number of pre-defined nonlinear elements is limited. In this method, the stiffness and mass orthogonal Ritz vectors of elastic structure system are used to reduce the nonlinearity of the system. The FNA method is a simple method based on dynamic equations (equilibrium, force- deformation and compatibility). The motion equation of a structure in time $(\mathrm{t})$ is expressed by matrix Equations 1 :

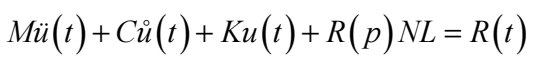

where, $M, C$ and $K$ are mass, relative damping and stiffness matrices, respectively. The size of these three square matrices is equal to total Number of displacements $(\mathrm{Nd})$ of the missing points. The elastic stiffness matrix $(k)$ does not consider the stiffness of nonlinear elements. The time-dependent vectors $\ddot{u}(t)$, $\stackrel{u}{u}(t), u(t)$ and $R(t)$ are momentary acceleration, displacement and applied external force. $R(t)_{\mathrm{NL}}$ is also a force vector given the total force of nonlinear members and is calculated at any temporal point with the trial and error. In all models studied in this research, the Ritz method (which considers the modes that essentially involve a large proportion of mass distribution and all modes are affected by base shear) has been used to determine the vibration period of structure.

\section{Studied Samples and Modeling Details}

The studied models all had the same properties in terms of material, frame dimensions, elements, as well as loading. Thus, in definition of frames, the concrete with the specifications of strength $\left(\mathrm{f}_{\mathrm{C}}^{\prime}\right)$ of $27.58(\mathrm{MPa})$, modulus of elasticity of $26855.58\left(\mathrm{~N} / \mathrm{mm}^{2}\right)$ and weight per volume of $23.56\left(\mathrm{kN} / \mathrm{m}^{3}\right)$ was used. The sections assigned to the frames were selected in accordance with Fig. 1 and the chosen frame of the studied hypothesized structure and the details of the frames were selected in accordance with Fig. 2. The properties of nonlinear elements were applied in accordance with (Table 10-7 of ASCE 41-13 in page 192) and (Table 10-14 of ASCE 41-13 in page 200) Fig. 3.
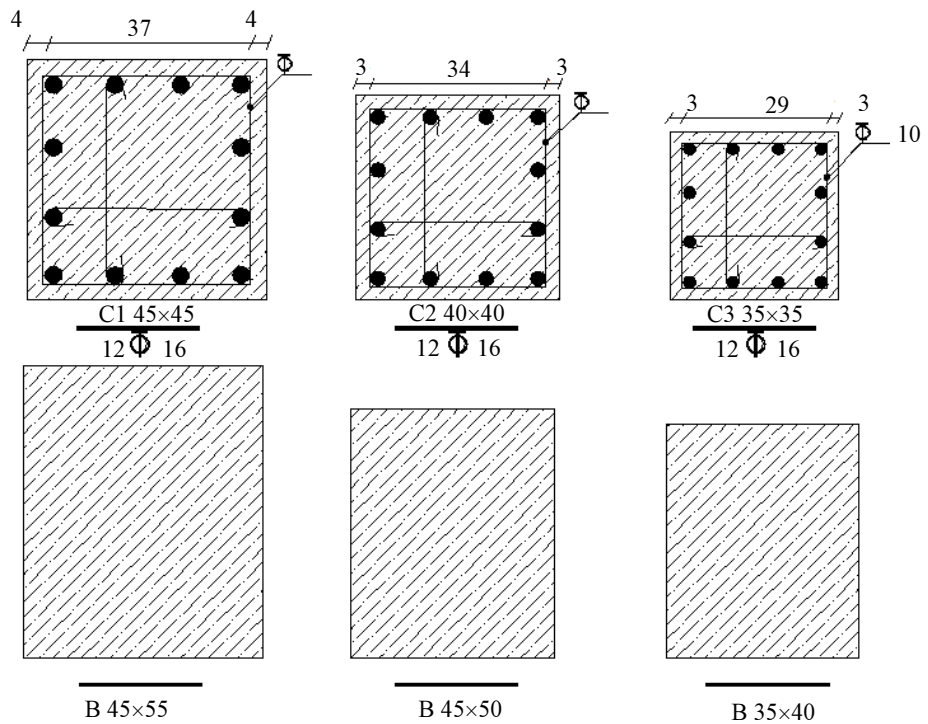

Fig. 1: Using sections for the column and beams $(\mathrm{cm})$ 

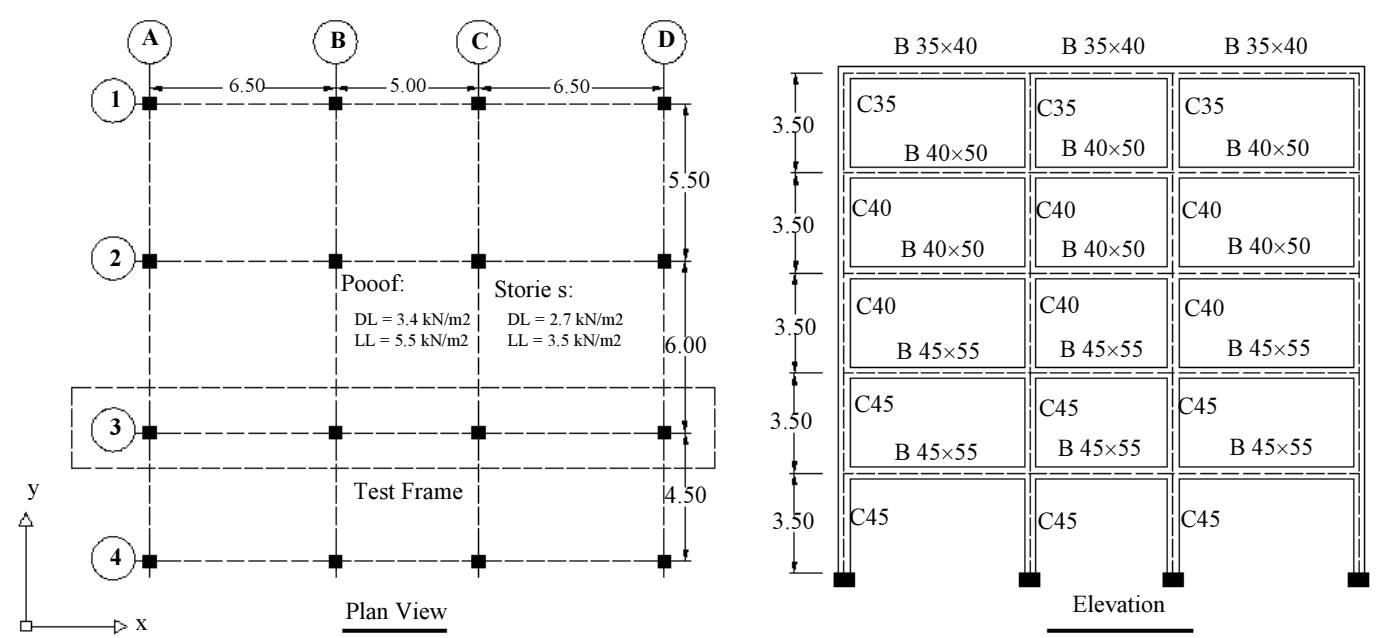

Fig. 2: Schematic plan view and elevation of the selected $\mathrm{RC}$ frame and loading amounts $(\mathrm{kN}, \mathrm{m})$

Table 1: Earthquakes Using in Analysis

\begin{tabular}{lccr}
\hline Earthquake & $\mathrm{RSN}$ & $\mathrm{dt}$ & $\mathrm{td}$ \\
\hline Abbar & 1633.0 & 0.02 & 31.56 \\
Kobe & 1111.0 & 0.01 & 12.37 \\
Tabas & 139.0 & 0.02 & 11.80 \\
Varzaghan & 5579101.0 & 0.02 & 8.68 \\
Ardabil & 1701.01 & 0.02 & 37.42 \\
S. Fernando & 63 & 0.01 & 15.47 \\
\hline
\end{tabular}

Also assigning the hinge properties to the models done as beam versus columns in all samples and all of the columns were installed on fixed base. The sections were selected in a way that the structural systems subjected to various peak earthquakes acceleration would experience different limit states and performance levels such as life safety and above. In loadings process, it was assumed that frames with the same loadings of 3.5 $\mathrm{kN}$ of floor live load, $2.7 \mathrm{kN}$ of floor dead load and 5.5 $\mathrm{kN}$ of roof live load and $3.4 \mathrm{kN}$ of roof dead load, which were applied as equivalent linear load to load-bearing beams in the structural system are analyzed. For the analyses, the time history functions of six recorded earthquakes mentioned in Table 1. Were provided, each of which was provided in five separate PGA (0.2-0.4-0.6-0.8 and 1) and was used in the analysis of the models.

\section{Experiments and Computer Based Analysis}

\section{Time Assessment}

In order to investigate the duration of analysis, a computer with dual-core $2.20 \mathrm{GHz}$ processor and $2 \mathrm{~GB}$ of RAM was used. The studied samples were all modeled in framework of AISC code and the hinge properties were applied to the frame in accordance with ASCE code. The other similar comparative study on nonlinear static and time history analysis by (Tran et al.,
2018) has been done The structure was analyzed by both FNA and NLTHA methods by preserving all conditions including properties of materials and sections Fig. 1, loading Fig. 2, as well as application of hinges Fig. 3, for models prepared in two different groups shown in Fig. 4 and the results were investigated using both nonlinear dynamic and time history nonlinear methods. Given all principles related to two nonlinear analytical methods, the models were finally examined with these two methods of analysis and the final duration of the analyses are collected as a statistical population for 120 models and time-dependent data were separately compared for two mentioned nonlinear analyses. These results are presented in Table 3 by the type of structural system and type of analysis for different earthquakes. The values presented in this table are the final results of data obtained from analysis outputs of 120 separated models and for PGA 1. Regardless of results for analysis time for various earthquakes, it is very obvious that duration of FNA is generally shorter and sometimes this difference is larger than several times.

From the results of Table 3, it can be concluded that the FNA in the frame only systems with nonlinear properties and less degrees of freedom are much faster than complex structural structures with more nonlinearity. This claim can be clearly seen in frames with dampers at the place of braces Fig. 4b. In comparison of the results recorded in the FNA for RC frame only and frame equipped by dampers with properties mentioned in Table 2, a two-fold increase in the duration of the analysis is observed and this somehow approves the principle of increased analysis time with an increase in number of nonlinear elements in this analysis.

Using numerical study of the values obtained for time of analyses, it's safe to say that the range of changes in speed of FNA compared to NLTHA is increased by 6.5- 
13 times. This range is specific to the time history functions of earthquakes that are used in this research, a numerical difference could be included with the expansion of the number of earthquakes as well as the type of structural systems examined in other studies. On the other hand, by analyzing the results recorded for the NLTHA, there is no indication that the analysis time is steadily increasing. For instance, the difference between values for the Kobe earthquake indicates that the time of nonlinear dynamic analysis depends also on the type of spectrum and the parameters of the studied earthquake, besides, a 3.5 fold increase in analysis time in the Tabas earthquake is another evidence that can be presented for this matter.

The principle of trust in the results of FNA depends on many factors and the most important ones include the accuracy in modeling, definition of model properties and analysis stages, complexity of system and type of studied structure. However, in general, in order to reduce analysis time even in models where there is a need for nonlinear analyses, one must determine which parameters of results and outputs are important. In other words, the final goal of the analysis should be considered. If the duration of the analysis for the group of design engineers is a determining factor, it is allowed to use the FNA considering all of its defined limitations. Thus, it can be said that in the performance-based design that requires nonlinear analysis and study on the hinges, in the structures with low importance factors and simple structural systems, one can be optimistic about the results of nonlinear analysis.

\section{Seismic Fragility Assessment of Models}

One of the important principles in accepting the results of analyses that have been performed with computer-aid methods and can be alternatives for each other is the achievement of close and similar results in accordance with proven values of manual numerical computations. In fact, the FNA is used with aim of reducing analysis time of structures that require nonlinear analysis. However, the accuracy of the results obtained from this analysis should also be considered in comparison with other nonlinear analyses, the accuracy of their results has been somehow approved by numerous researchers. The final goal of this research is based on the principle that the accuracy of results of nonlinear analyses on several models has been investigated with different structural systems (for measuring the efficiency of analysis in normal and complex systems) and the final results from the comparison of models are presented as seismic fragility curves for several determinants of the accuracy of the results that is obtained from the outputs of each model. As mentioned in the previous section, for this purpose, a five-story RC structure in two different structural systems, RC MRF only and MRF-VD, was separately simulated in computer models. These models were initially studied with NLTHA and then with FNA. To provide more realistic final results with higher accuracy, the time history functions of six earthquakes were prepared for each $0.2 \mathrm{~g}$ and each structural system was separately investigated 30 times for both types of nonlinear analysis and for each PGA.

Table 2: Exponential damper properties (kip/in)

\begin{tabular}{lll}
\hline Stiffness & $\begin{array}{l}\text { Damping } \\
\text { Coefficient }\end{array}$ & $\begin{array}{l}\text { Damping } \\
\text { Exponent }\end{array}$ \\
\hline 20 & 50 & 0.5 \\
\hline
\end{tabular}

Table 3: Computational Time (Sec)

\begin{tabular}{llrl}
\hline Structural system & Earthquake & NLTH & FNA \\
\hline RC Frame Only & Abbar & 15.00 & 2.00 \\
& Kobe & 49.00 & 2.00 \\
& Tabas & 11.00 & 2.00 \\
& Varzaghan & 15.00 & 2.00 \\
& Ardabil & 15.00 & 2.00 \\
& S. Fernando & 21.00 & 2.00 \\
Standard Deviation & & 14.09 & 0.00 \\
Mean & & 21.00 & 2.00 \\
RC Frame with Dampers & Abbar & 39.00 & 5.00 \\
& Kobe & 52.00 & 4.00 \\
& Tabas & 45.00 & 4.00 \\
& Varzaghan & 37.00 & 5.00 \\
Standard Deviation & Ardabil & 38.00 & 4.00 \\
Mean & S. Fernando & 41.00 & 4.00 \\
\hline
\end{tabular}


Numerical Acceptance Criteria for Linear Procedures Reinforced Concrete Beam-Column Joints

\begin{tabular}{|c|c|c|c|c|c|c|c|}
\hline & \multirow[b]{5}{*}{ Conditions } & \multicolumn{6}{|c|}{$m$-Factors } \\
\hline & & \multicolumn{6}{|c|}{ Performance level } \\
\hline & & & \multicolumn{5}{|c|}{ Component Type } \\
\hline & & & \multicolumn{3}{|c|}{ Primary } & \multicolumn{2}{|c|}{ Secondary } \\
\hline & & & $\mathrm{IO}$ & $\overline{\mathrm{LS}}$ & $\overline{\mathrm{CP}}$ & $\mathrm{LS}$ & $\mathrm{CP}$ \\
\hline \multicolumn{8}{|c|}{$\begin{array}{l}\text { Conditions i. Interior joints (for classification of joints, refer to Fig. 10-3) Transverse reinforcement" } \\
P^{b}\end{array}$} \\
\hline$\overline{A_{g} f_{c}^{\prime}}$ & & $\overline{V_{m}}$ & & & & & \\
\hline$\leq 0.1$ & $\mathrm{C}$ & $\leq 1.2$ & 1 & 1 & 1 & 3 & 4 \\
\hline$\leq 0.1$ & $\mathrm{C}$ & $\geq 1.5$ & 1 & 1 & 1 & 2 & 3 \\
\hline$\geq 0.4$ & $\mathrm{C}$ & $\leq 1.2$ & 1 & 1 & 1 & 3 & 4 \\
\hline$\geq 0.4$ & $\mathrm{C}$ & $\geq 1.5$ & 1 & 1 & 1 & 2 & 3 \\
\hline$\leq 0.1$ & $\mathrm{NC}$ & $\leq 1.2$ & 1 & 1 & 1 & 2 & 3 \\
\hline$\leq 0.1$ & $\mathrm{NC}$ & $\geq 1.5$ & 1 & 1 & 1 & 2 & 3 \\
\hline$\geq 0.4$ & $\mathrm{NC}$ & $\leq 1.2$ & 1 & 1 & 1 & 2 & 3 \\
\hline \multirow{2}{*}{\multicolumn{8}{|c|}{$\begin{array}{l}\geq 0.4 \\
\text { Conditions iii. Other joints (for classification of joints, refer to Fig. 10-3) Transverse reinforcement" }\end{array}$}} \\
\hline & & & & & & & \\
\hline$P^{b}$ & & $V^{d}$ & & & & & \\
\hline$\overline{A_{g} f_{c}^{\prime}}$ & & $\overline{V_{m}}$ & & & & & \\
\hline$\leq 0.1$ & $\mathrm{C}$ & $\leq 1.2$ & 1 & 1 & 1 & 3 & 4 \\
\hline$\leq 0.1$ & $\mathrm{C}$ & $\begin{array}{l}-1.2 \\
\geq 1.5\end{array}$ & 1 & 1 & 1 & 2 & 3 \\
\hline$\geq 0.4$ & $\mathrm{C}$ & $\leq 1.2$ & 1 & 1 & 1 & 3 & 4 \\
\hline$\geq 0.4$ & $\mathrm{C}$ & $\geq 1.5$ & 1 & 1 & 1 & 2 & 3 \\
\hline$\leq 0.1$ & $\mathrm{NC}$ & $\leq 1.2$ & 1 & 1 & 1 & 2 & 3 \\
\hline$\leq 0.1$ & $\mathrm{NC}$ & $\geq 1.5$ & 1 & 1 & 1 & 2 & 3 \\
\hline$\geq 0.4$ & $\mathrm{NC}$ & $\leq 1.2$ & 1 & 1 & 1 & 1.5 & 2 \\
\hline$\geq 0.4$ & $\mathrm{NC}$ & $\geq 1.5$ & 1 & 1 & 1 & 1.5 & 2 \\
\hline
\end{tabular}

Modeling parameters and Numerical Acceptance Criteria for Nonlinear Procedures Reinforced Concrete Beams

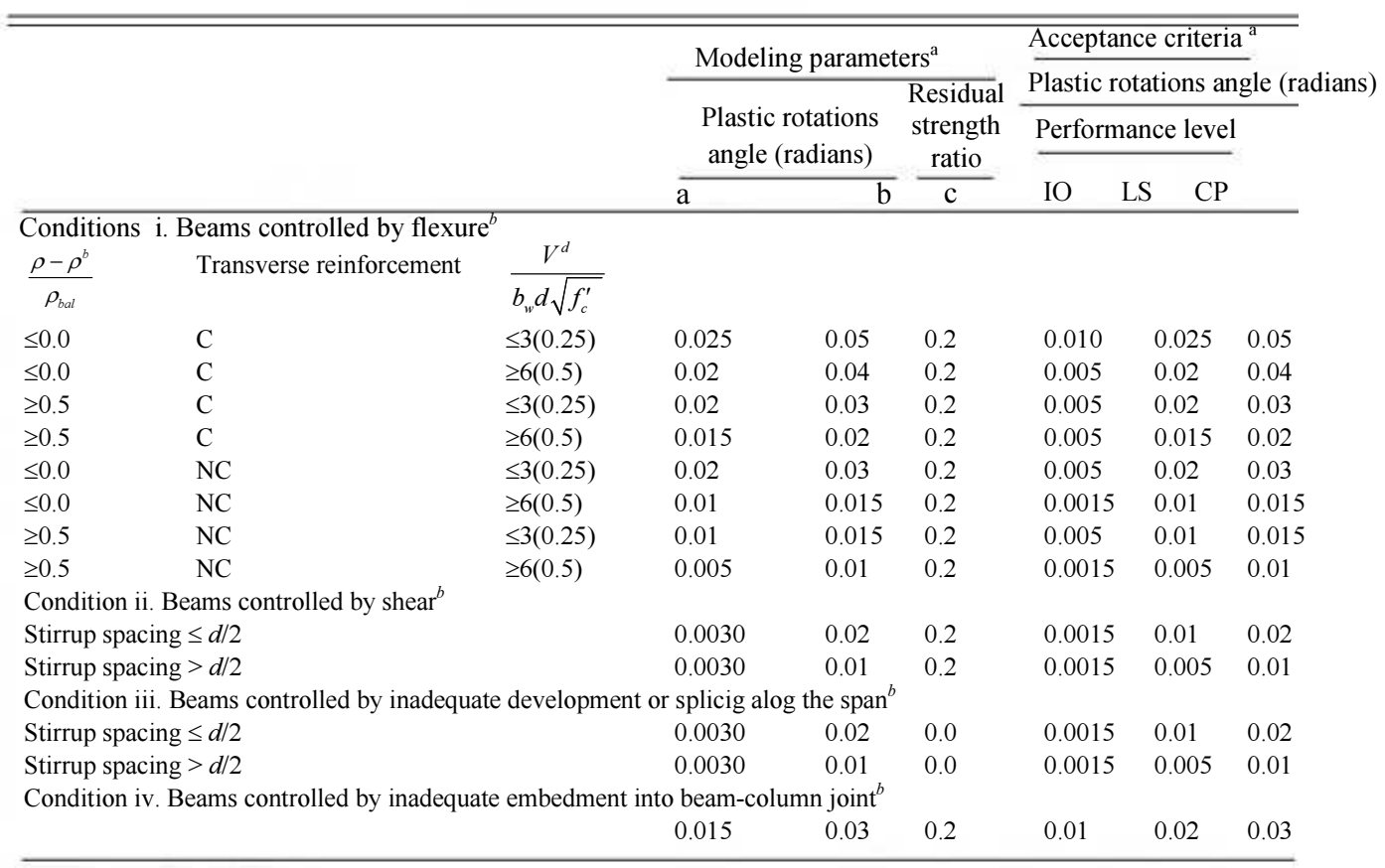

Fig. 3: Assigned hinge parameters for RC elements according to ASCE 41-13 


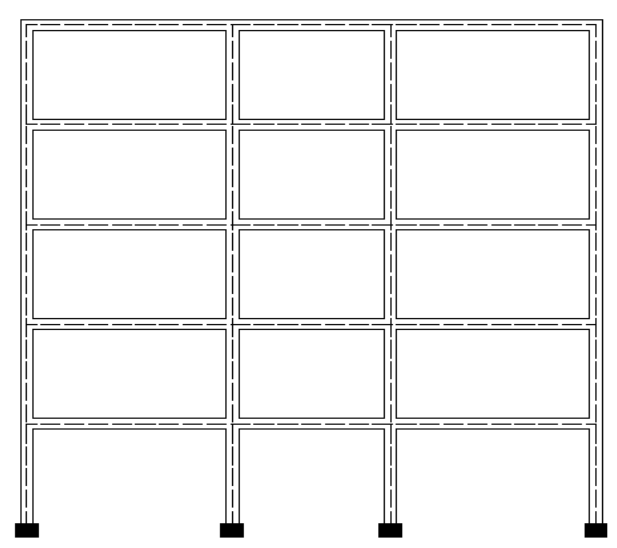

(a)

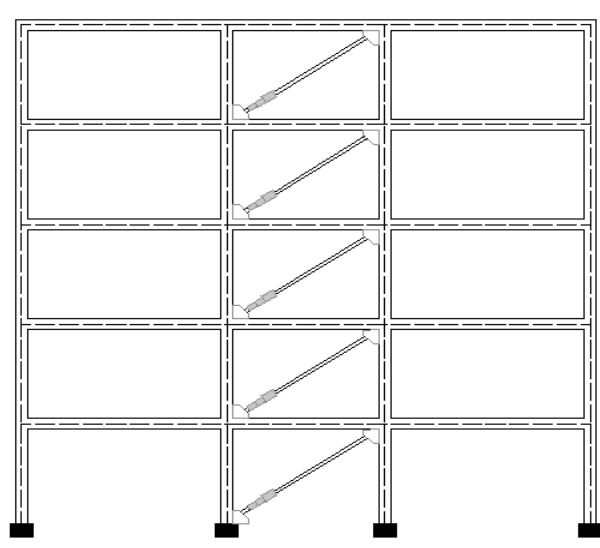

(b)

Fig. 4: Elevation view of the studied samples and considered structural systems (a) RC moment resistance frame (b) RC frame equipped by dampers

In other words, the structures were completely affected by the desired earthquake function gradually and in five successive steps. This was also effective in measuring the accuracy of analyses in addition to plotting the seismic fragility curve. In the following, a summary of the report and the results of these two studied systems are presented.

\section{Moment Resistance RC Frame Only}

After the time assessment of models, to ensure that the results of both types of analysis can be considered as design criteria, the seismic performance of all 120 models was also studied in the second phase of the research. In the first step of the second phase of the study, the RC frame subjected to the determined earthquakes was investigated. Although the seismic performance of a structure can be examined from various aspects, in this research, the values of displacements (maximum drift) has been provided as the acceptance criterion for the correctness of the results as seismic fragility curves for both nonlinear analyses.

Figure 5, the seismic fragility curve for the RC frame only, Fig. 4a has been shown. It is obvious that with an attention to the results obtained for the FNA from PGA 0.4, a significant large distance from the NLTHA results is achieved. A significant difference of about five folds occurs in the results of two analyses after the PGA 0.6 , so that in the results of PGA 0.8, a maximum difference can be seen. Obviously, the distance of damage to the system from the real value can be clearly seen in these curves.

Moreover, in the FNA analysis, the number of elements entering the nonlinear behavior after PGA 0.4 is not significantly increased (there were differences in the number of nonlinear hinges as well as the performance level in various earthquakes) Fig. 6. However, similar elements in the NLTHA analysis also appeared in the LS performance level. In general, it can be concluded that for this system, FNA shows a greater damage to the structure than the real value (obtained from the more accurate analysis of NLTHA) and in terms of both important parameters of design, economic design and structural performance, the design engineer will be challenged.

\section{RC Frame with Viscous-Elastic Dampers}

In the second step of the second phase of the research, the structural system of MRF_VD was modeled Fig. 4b. Seismic behavior of structures equipped by dampers has been investigated by some researchers, (Shakibabarough et al., 2016) and one all of the important factors for assessment is estimation of displacements by analysis. In this study dampers were selected from commercial products brochure of a company then the assumed devices characteristics were assigned to the models in Sap 2000, Table 2. Subjected to the same earthquakes, the structure was analyzed with two nonlinear methods and the values of maximum drift for the system was recorded in all earthquakes and its seismic fragility curve was prepared Fig. 7.

As can be seen from the curve, the distance created in the proportion of structural responses in both analyses are similar to the first case of study, while the number of degrees of freedom in this system as well as the hinges in both performance levels of IO and LS was higher than the first case Fig. 8. The accuracy in providing results seems slightly more acceptable. In fact, the performance levels made in the structure for two methods of analysis are not far from each other in terms of conditions shown for the hinges, but in this system, it is explicitly stated that the seismic behavior of the structure in both types of analysis until PGA 0.6 was very close and an almost four-fold difference in the results occurs after this PGA. As a result, for this structural system, it can be said that FNA estimates a greater damage to the structure than the real values. 


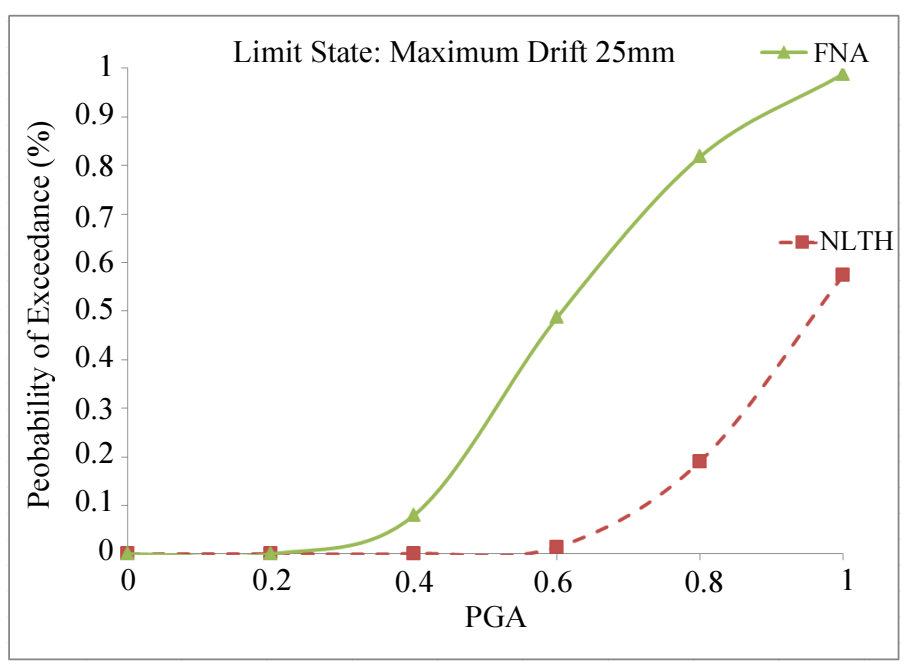

Fig. 5: Fragility curve for the RC frame only

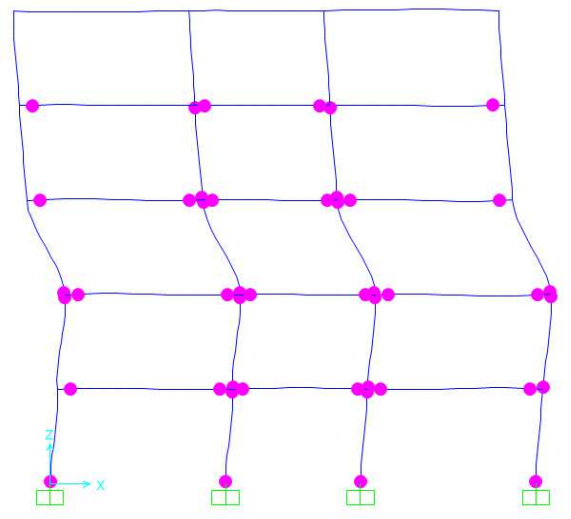

(San Francisco Earthquake-PGA 1.0)

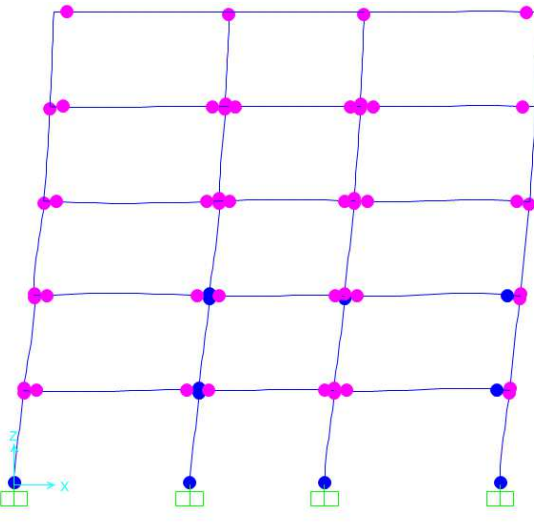

(Kobe Earthquake-PGA 1.0)

Fig. 6: Selected results for seismic performance and hinge conditions

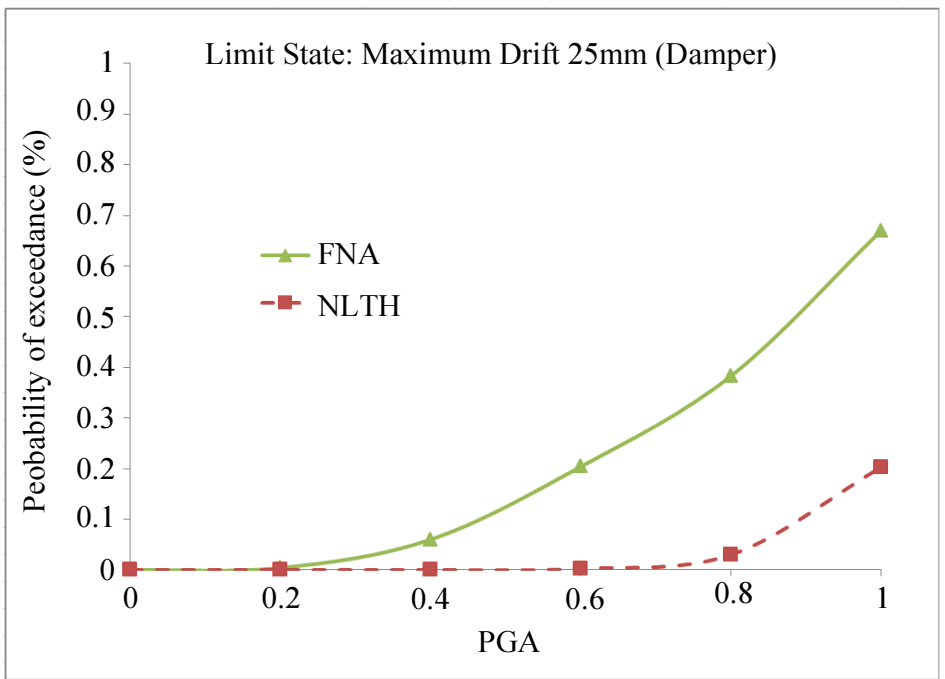

Fig. 7: Fragility curve for the RC frame supported by dampers 


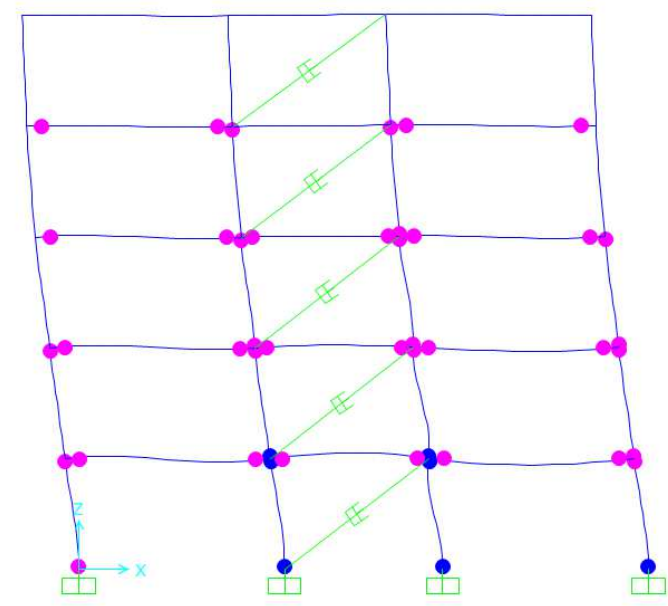

(San Francisco Earthquake-PGA 1.0)

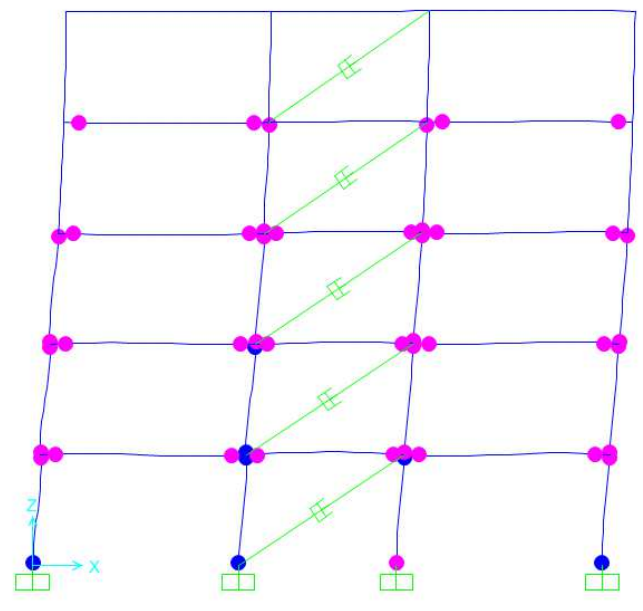

(Kobe Earthquake-PGA 1.0)

Fig. 8: Selected results for seismic performance and hinge condition

\section{Conclusion}

From the process of this research and the final results, it can be concluded that given the need for design as well as the importance of parameters such as the time and cost of project, the aforementioned nonlinear analyses in this study can be used. In this research and with studying the samples, it was found that FNA, despite its deficits, can be used in cases where the designer intends to observe nonlinear behavior of structures with small importance factor as well as fewer nonlinear elements. Still, it should be noted that FNA has higher speed of implementation than NLTHA by several times.

Furthermore, given that the emphasis of this study is on comparison of the outputs of the FNA and NLTHA analysis in structures that are equipped by dampers, it should be said that given the resulting seismic fragility curves, the accuracy of the outputs from the FNA analysis in structures equipped with dampers is less reliable than the real values obtained from NLTHA. This result is clearly confirmed in the visual inspection of the fragility curves related to this structural system. However, in the structures with RC frame only, although the accuracy of FNA results has a distance from the more accurate analysis (NLTHA), due to the limited nonlinear elements as well as the degrees of freedom of this system, one can be optimistic about the results obtained from the FNA analysis and the results are acceptable for this type of structural system. However, this is doubted in the final results of structural systems similar to more nonlinear elements. Finally, it can be said that FNA achieves higher values of damage to the structure than the real values in comparison with the NLTHA.

\section{Author's Contributions}

Ali A. R. Alilou: Computer-aid modeling, testing and analysis, author of paper.

M. Pouraminian: Project leader, provided the research topic and guided the research development, data analysis and contribute to the writing of the paper.

\section{Ethics}

This article is an original research paper. There is no ethical issues that may arise after the publication of this manuscript.

\section{References}

Ashrafi, H.R., P. Beiranvand, M. Pouraminian and M.S. Moayeri, 2018. Examining the impact of sheet placement and changes in waves characteristics on behavior of wavy steel shear wall. Case Stud. Construct. Mater., 9: e00180- e00180.

CSI, 2009. CSI analysis reference manual for SAP2000. ETABS, SAFE and CSI Bridge, Berkeley, California.

Hariri-Ardebili, M.A. and V.E. Saouma, 2016. Seismic fragility analysis of concrete dams, a state-of-the-art review. Eng. Structures, 128: 374-399.

Islam, A.S., 2011. Non-linear time domain analysis of base isolated multi-story building under site specific bi-directional seismic loading. Automat. Construct., 22: 554-566.

Pouraminian, M., M. Amarlou, S. Pourbakhshian and R. Khodayari, 2015. Evaluation of the vibrational properties of three-span continuous concrete bridge by dynamic finite element method. J. Civil Eng. Urbanism, 5: 27-30. 
Pouraminian, M. and M. Ghaemian, 2015. Shape optimisation of concrete open spandrel arch bridges. Građevinar, 67: 1177-1185.

Pouraminian, M. and M. Ghaemian, 2017. Multi-criteria optimization of concrete arch dams. Sci. Iranica. Transact. Civil Eng., 24: 1810-1810.

Ras, A. and N. Boumechra, 2016. Seismic energy dissipation study of linear fluid viscous dampers in steel structure design. Alexandria Eng. J., 55: 2821-2832.

Salem, Y.S., A.B. Lucas and G.M. Gad, 2017. Analytical fragility curves for reinforced concrete dual system subjected to seismic loads. Proceedings of the International Congress and Exhibition, Sustainable Civil Infrastructures: Innovative Infrastructure Geotechnology, (IIG' 17), pp: 144-157.

Sayyar-Roudsari, S., S.A. Hamoush, S.M. Soleimani and R. Madandoust, 2018a. Evaluation of large-size reinforced concrete columns strengthened for axial load using fiber reinforced polymers. Eng. Structures.

Sayyar-Roudsari, S., S. Hamoush, S. Soleimani, T. AbuLebdeh and M. Haghighifar, 2018b. Analytical study of reinforced concrete beams strengthened by FRP bars subjected to impact loading conditions. Am. J. Eng. Applied Sci., 11: 407-425.
Seo, J.J., W. Hu and B. Davaajamts, 2015. Seismic performance evaluation of multistory reinforced concrete moment resisting frame structure with shear walls. Sustainability, 7: 14287-14308.

Shakibabarough, A., M. Valinejadshoubi and A. Bagchi, 2016. Effects of damper locations and base isolators on seismic response of a building frame. Int. J. Civil, Environ. Structural, Construct. Architectural Eng., 10: 718-723.

Soleimani, M.S. and S. Sayyar-Roudsari, 2015. Analytical study of reinforced concrete beams tested under impact loading. Proceedings of the 4th International Workshop Performance Protection Strengthening Structures Under Extreme Loading, Jun. 28-30, East Lansing, MI, USA, pp: 620-627.

Tran, Q.H., J. Huh, V.B. Nguyen, A. Haldar and C. Kang et al., 2018. Comparative study of nonlinear static and time-history analyses of typical korean STS container cranes. Adv. Civil Eng.

Wilson, E.L. M.W. Yuan and J.M. Dickens, 1982. Dynamic analysis by direct superposition of Ritz vectors. Earthquake Eng. Structural Dynamics, 10: 813-821. 